\title{
Uso de modelos digitais de terreno no monitoramento da Praia do Forno, Armação dos Búzios, RJ, Brasil \author{
Búzios, RJ, Brazil
} \\ Use of digital terrain models in monitoring Forno beach, Armação dos
}

\author{
Paulo Renato Gomes Osilieri $^{\text {ad }}$, Fabio Ferreira Dias ${ }^{\text {ae }}$, Alberto Luis da Silva ${ }^{\text {af }}$, Agenor Cunha \\ da Silva ${ }^{\text {bg }}$, João Wagner de Alencar Castro ${ }^{\text {ch }}$ \\ ${ }^{\mathrm{a}}$ Universidade Federal Fluminense, ${ }^{\mathrm{b}}$ Marinha do Brasil, ${ }^{\mathrm{c}}$ Universidade Federal do Rio de Janeiro

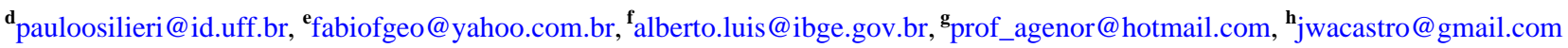

\begin{abstract}
RESUMO
O presente artigo tem como objetivo descrever uma metodologia para ser utilizada em monitoramento de ambientes costeiros, através da geração de Modelos Digitais de Terreno (MDT), a partir da coleta de dados altimétricos por equipamentos DGPS (Sistema de Posicionamento Global Diferencial) operados no modo relativo Semicinemático, bem como discutir os resultados e aplicações, concluindo que se trata de uma técnica bem eficaz se for aplicada a praias de pequena extensão.
\end{abstract}

Palavras-chave: Praias; GPS; Balanço Sedimentar; Modelo Digital de Terreno.

\begin{abstract}
This paper aims to describe a methodology to be used in the monitoring of coastal environments, through the creation of Digital Terrain Models (MDT) from the altimetric data collection by DGPS (Differential Global Positioning System) equipment operated in Stop and Go mode and to discuss the results and applications, concluding that it is a very effective technique if applied in beaches of small extent.
\end{abstract}

Keywords: Shores; GPS; Sediment Balance; Digital Terrain Models.

\section{Introdução}

A compreensão da dinâmica costeira é de fundamental importância na análise ambiental de diversas áreas do território brasileiro, o qual apresenta um litoral com extensão aproximada de $8.500 \mathrm{~km}$. Dentro dessa larga faixa de terra está o litoral do estado do Rio de Janeiro, com aproximadamente $640 \mathrm{~km}$ de dimensão, onde se encontra a Praia do Forno, no município de Armação dos Búzios, localidade em que foi empregado o método para geração de Modelo Digital de Terreno (MDT) descrito neste trabalho.

O monitoramento ambiental consiste na realização de medições e/ou observações específicas, dirigidas a alguns poucos indicadores e parâmetros, com a finalidade de verificar se determinados impactos ambientais estão ocorrendo, podendo ser dimensionada sua magnitude e avaliada a eficiência de eventuais medidas preventivas adotadas (Bitar \& Ortega, 1998). Existem diversas formas de monitoramento de ambientes costeiros, como o uso de técnicas de sensoriamento remoto e geoprocessamento, testes e experimentos químicos, análise de indicadores biológicos, entre outras.
Podemos destacar o trabalho de Pasolini (2005), que, a partir da análise morfodinâmica da praia de Marataízes, estabeleceu uma relação entre o tamanho dos grãos do sedimento e a morfologia do perfil da praia. O autor diagnosticou a quantidade necessária de sedimentos para o engordamento artificial da praia com o objetivo de colocá-la em estado de equilíbrio morfodinâmico. Tabosa (2002) realizou monitoramento na região de São Bento do Norte e Caiçara do Norte, no litoral do estado do Rio Grande do Norte, com o objetivo de caracterizar a dinâmica sedimentar do litoral em questão através de dados relacionados à dinâmica costeira (ventos, correntes, marés e ondas), levantamentos topográficos, análises sedimentológicas e imagens de satélite. Esse monitoramento permitiu concluir que a movimentação dos sedimentos exibe um padrão cíclico, atingindo maiores oscilações nos meses de verão e inverno, classificando as praias como reflectivas, o que enquadra essa região como fortemente vulnerável a processos erosivos. Amaro \& Araújo (2008) executaram um estudo que teve como intuito a análise multitemporal da morfodinâmica costeira entre os municípios de Grossos e Tibau, no estado do Rio Grande do Norte. Por meio do reconhecimento de feições de campo, perfis de praia e 
da interpretação de imagens de sensores orbitais de diferentes datas das últimas quatro décadas, através de técnicas de geoprocessamento para a elaboração de mapas temáticos dos recursos naturais e da evolução da linha de costa, concluíram que tais técnicas constituem importantes ferramentas ao gerenciamento ambiental, denotando as tendências das variações antrópicas e naturais, possibilitando o planejamento adequado para o desenvolvimento da região.

Silva et al. (2008) fizeram um estudo na praia de Itaipuaçu, município de Maricá (RJ), buscando compreender o comportamento morfológico e sedimentar desse litoral através de perfis topográficos associados com análises granulométricas, que permitiram concluir que a parte oeste do arco de praia é mais dinâmica e vai reduzindo de intensidade em direção a leste. Pereira (2008) analisou o risco geológico do arco praial do Peró, município de Cabo Frio, através da execução de perfis de praia com DGPS no modo semicinemático (stop and go), interpretação de dados do regime de ondas e ventos, e análises granulométricas, trabalhando as informações adquiridas em modelos matemáticos para a obtenção da taxa de transporte de sedimentos transversal e longitudinal, apresentando como conclusão de seu trabalho um mapa que classifica o risco geológico do arco praial em alto, médio e baixo. Castro et al. (2011) realizaram monitoramento da praia das Tartarugas, no município de Rio das Ostras, no estado do Rio de Janeiro, através de análise temporal de imagens aéreas de 1975 e 2003 e execução de oito perfis transversais de praia, em três datas (fevereiro de 2009, junho de 2009 e janeiro de 2010) com aparelhos DGPS operados no modo semicinemático. A execução dessa metodologia, através de técnicas de geoprocessamento, possibilitou concluir que a linha de praia sofreu recuo de 40 metros em 28 anos, com taxa de recuo de aproximadamente 1,4 metros/ano. Os dados dos perfis de praia analisados permitiram identificar erosão em cinco dos oito perfis transversais de praia e a taxa de retrogradação da praia no intervalo de monitoramento. De Oliveira \& Calliari (2006) realizaram um diagnóstico da morfodinâmica da praia do Mar Grosso, em São José do Norte, no estado do Rio Grande do Sul, através de perfis de praia, realizados mensalmente, de março de 2004 a abril de 2005, utilizando uma Estação Total, concluindo que as seções da praia analisadas possuíam um comportamento similar, em que o aumento das mudanças morfológicas e volumétricas ocorreram à medida que se aproximavam do molhe Leste. Mazzer \& Dillenburg (2009) executaram uma análise temporal da variação da linha de costa, em dois intervalos distintos (1938-2002 e 1998-2002), de cinco praias da costa sudeste da Ilha de Santa Catarina, através de fotografias aéreas, processadas por meio de técnicas de geoprocessamento. A conclusão foi de que as praias apresentavam características erosivas distintas, uma vez que na análise interdecadal (19382002) a variação da linha de costa é influenciada pela configuração espacial (orientação, exposição) e por aspectos morfodinâmicos a médio prazo (estágio morfodinâmico, rotação praial), e na análise interanual (1998-2002), as variações foram influenciadas por eventos de alta energia e variações sazonais nas condições hidrodinâmicas e meteorológicas. Rocha et al. (2010) fizeram um monitoramento da variação de linha de costa no litoral do município de Japaratinga, estado de Alagoas, no período 2007-2008 (uma campanha em cada ano), através da análise da HWL (High Water Line) correspondendo a 2,8m acima do referencial de nível das marés. O traçado da linha de costa foi realizado por meio da extração da HWL de um MDE obtido pela interpolação de pontos coletados com aparelho DGPS no modo cinemático na praia, concluindo que a linha de praia obteve deslocamento de $6 \mathrm{~m}$ para o período analisado. Gonçalves et al. (2010) utilizaram, no litoral do município de Vila Nova de Gaia, em Portugal, uma câmera digital de alta resolução acoplada a um avião para que durante o voo fosse fotografada toda a área de estudo. Além das cotas obtidas pela interpretação e processamento dos pares estereoscópicos, foram feitos levantamentos no terreno com GPS de dupla frequência, com a intenção de ratificar as informações obtidas com a análise e processamento das fotografias. Para a geração do MDT, foram manuseados os pares estereoscópicos no programa BLUH, desenvolvido na Universidade de Hannover, que aplica correlação automática por mínimos quadrados com crescimento de regiões (Gonçalves et al. 2010).

O presente artigo tem a intenção de descrever uma metodologia para extração de MDT através da operação de equipamentos GPS para aquisição de dados altimétricos e planimétricos no modo relativo semicinemático e pontos de controle no modo relativo estático, já aplicada por Andrade et al. (2011), na Praia Brava, no município de Armação dos Búzios.

\section{2. Área de estudo}

A praia do Forno localiza-se no município de Armação dos Búzios-RJ (figura 1), apresentando uma extensão de aproximadamente 120 metros e 25 metros de largura. A configuração geomorfológica protege a praia do Forno de grandes transformações causadas pela dinâmica costeira local, uma vez que a mesma está próxima de um promontório que reduz os impactos erosivos provocados pela ação das ondas do oceano. 


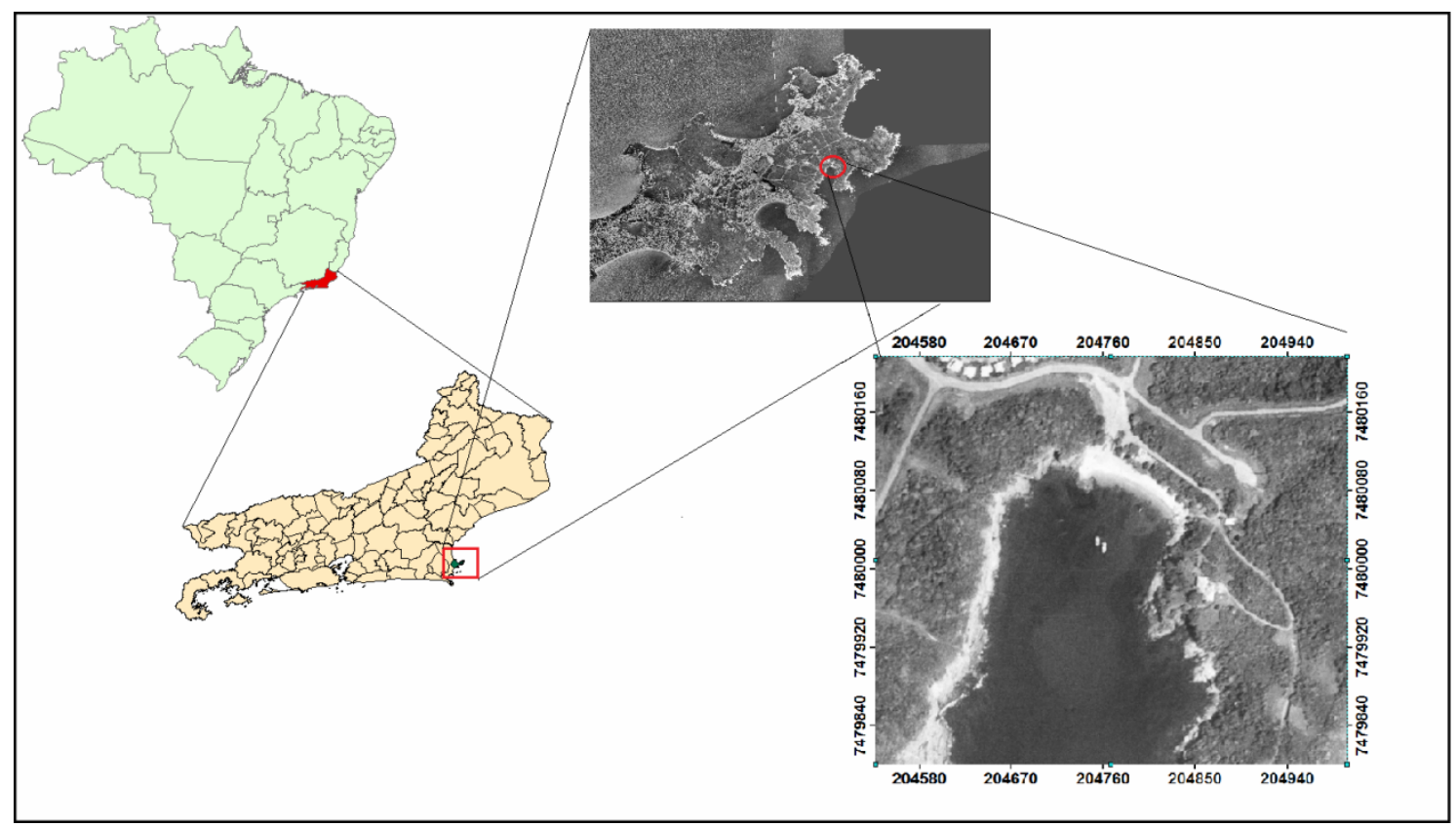

Figura 1: Localização da Praia do Forno. Projeção: UTM, Datum: SAD69, Fuso: 23K

\section{Técnicas de levantamento GPS}

Para o posicionamento com GPS, existem basicamente duas técnicas de levantamento utilizadas na determinação de coordenadas (Monico 2007):

a) Posicionamento Absoluto ou Posicionamento por Ponto, quando apenas um receptor GPS é utilizado na determinação das coordenadas. Trata-se de um método em que as coordenadas são determinadas diretamente a partir das órbitas dos satélites e, portanto, ao geocentro. É comumente utilizado na navegação, como em embarcações, automóveis e em levantamentos topográficos expeditos realizados em campo, ou seja, em atividades que não requerem maior precisão. Por outro lado, quando se trabalha com receptores de dupla frequência, pode-se utilizar a técnica de posicionamento por ponto preciso e, nesse caso, obter resultados mais exatos.

b) Posicionamento Relativo, quando se utilizam pelo menos dois receptores GPS rastreando dados simultaneamente dos mesmos satélites, sendo que um dos receptores deve estar posicionado em uma estação de referência e, portanto, com coordenadas conhecidas. Neste posicionamento, as coordenadas são determinadas para o receptor posicionado sobre o ponto de interesse, a partir de um referencial materializado pela estação de referência. Trata-se de uma técnica de posicionamento que permite modelar boa parte dos erros inerentes às observações GPS, tais como efeitos de ionosfera e troposfera gerados na propagação do sinal. Como os dois receptores coletam dados simultaneamente, é possível estabelecer uma relação entre as leituras e efetuar um ajuste ou uma correção diferencial com o auxílio de um programa específico.

O uso de DGPS está associado à determinação de coordenadas através de um posicionamento. Existem três tipos de posicionamento relativo nos levantamentos com GPS (Monico 2007):

a) Estático: Utilizam-se no mínimo dois receptores fixos, ocupando simultaneamente as estações (base e móvel) e observando os mesmos satélites para a determinação de uma linha de base. A precisão deste tipo de posicionamento depende do tempo de rastreio e do tipo de equipamento utilizado;

b) Cinemático: $\mathrm{O}$ receptor coleta dados enquanto se desloca. Trata-se da determinação de uma trajetória. No caso de levantamento relativo, a base deve estar imóvel sobre uma estação de referência;

c) Semicinemático (Stop and Go): Trata-se de um método de posicionamento em que o receptor permanece em sintonia com os satélites durante o deslocamento, mas sem coletar dados, o que é feito somente quando estiver estático e por um determinado tempo de rastreio definido pelo operador.

\section{Metodologia}

A metodologia utilizada para geração de MDTs neste trabalho consistiu em levantamentos topográficos a partir de equipamentos DGPS (figura 2). Para este estudo foi escolhido o modo semicinemático, ficando a cargo do operador a coleta dos pontos (figuras 3 e 4), além da aquisição de pontos de controle com o mesmo aparelho no modo estático, permitindo a obtenção de 
pontos com maior precisão para ratificar a veracidade do modelo extraído através dos dados obtidos com DGPS no modo semicinemático. Foi montada uma base próxima à praia investigada utilizando a estação 3073D do IBGE presente na região. O polígono usado para definir os limites da praia do Forno foi desenvolvido com base em observações da ortofoto do município de Armação dos Búzios (figura 5).

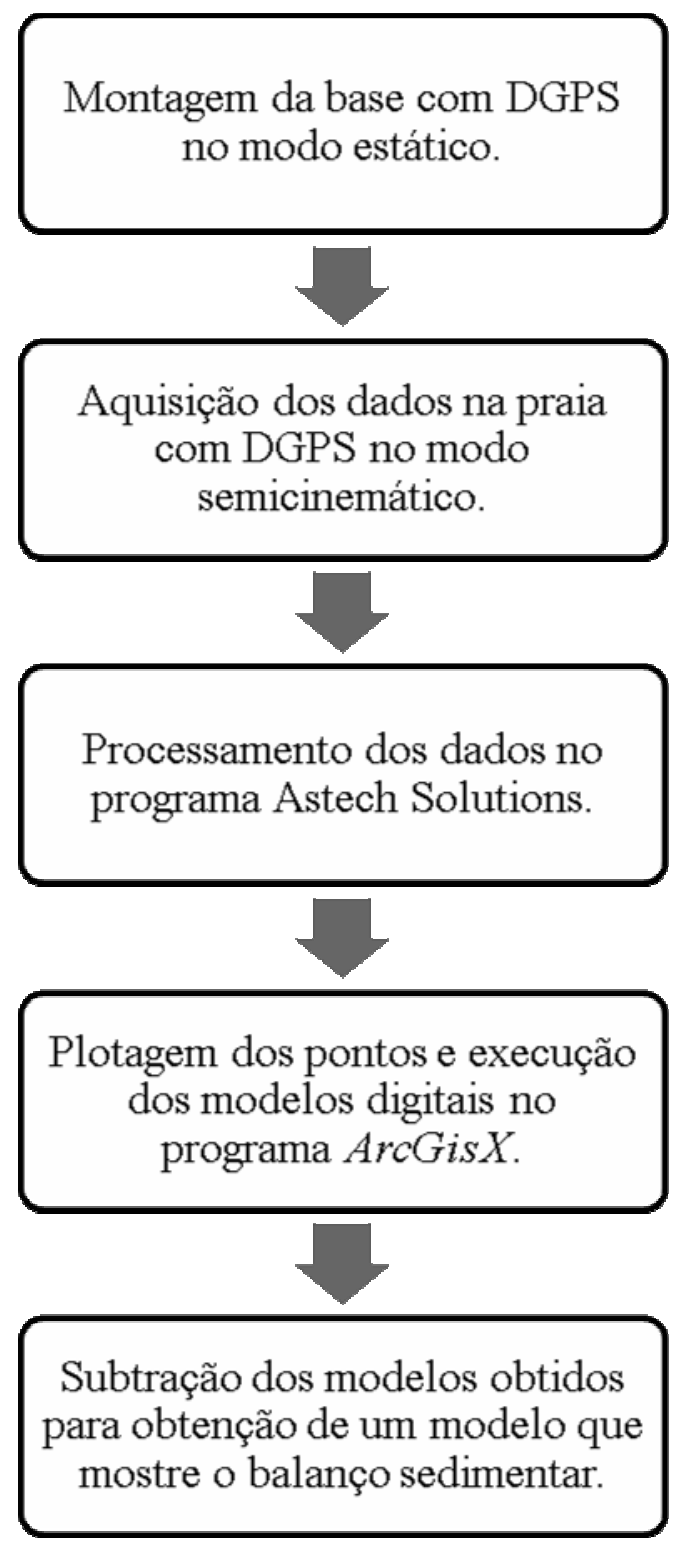

Figura 2: Fluxograma da metodologia descrita

Após a aquisição dos dados pelo DGPS, os mesmos foram descarregados em gabinete e processados no software Astech Solutions. Com os dados processados, os pontos obtidos com o DGPS foram trabalhados no programa ArcGis X para a confecção dos modelos altimétricos (figuras 6 e 7) através da ferramenta Topo to Raster disponível através do caminho 3D Analyst Tools - Raster Interpolation - Topo to Raster.
A utilização da ferramenta Topo to Raster foi escolhida por meio de revisão bibliográfica de trabalhos como o de Nogueira \& Amaral (2009), que compara dois métodos de interpolação de dados (Topo to Raster e Krigagem) para pontos com informações de batimetria no estado do Rio Grande do Norte. Concluiu-se que a ferramenta Topo to Raster apresenta resultados com mais informações para elaboração de superfícies batimétricas, permitindo avaliar detalhes de estruturas discretas apresentadas no relevo, como canais de fluxos, submersos, transversais às linhas de costa que não foram visualizados pelo método da Krigagem.

Após a extração dos MDTs, os modelos foram subtraídos através da ferramenta Cut Fill, para que fosse informado se o ambiente apresentou acresção ou remoção de sedimentos, conforme mostram as figuras 8 e 9.

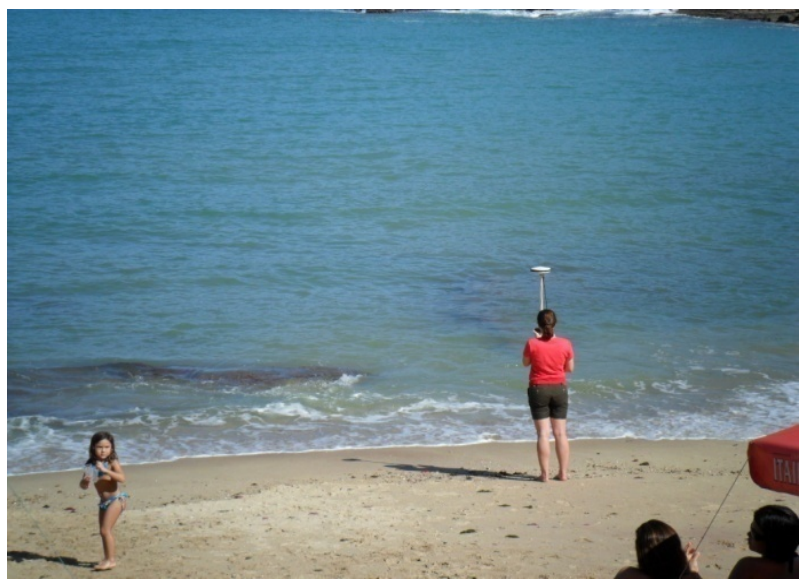

Figura 3: Aquisição de dados com utilização de DGPS no modo semicinemático no pós-praia

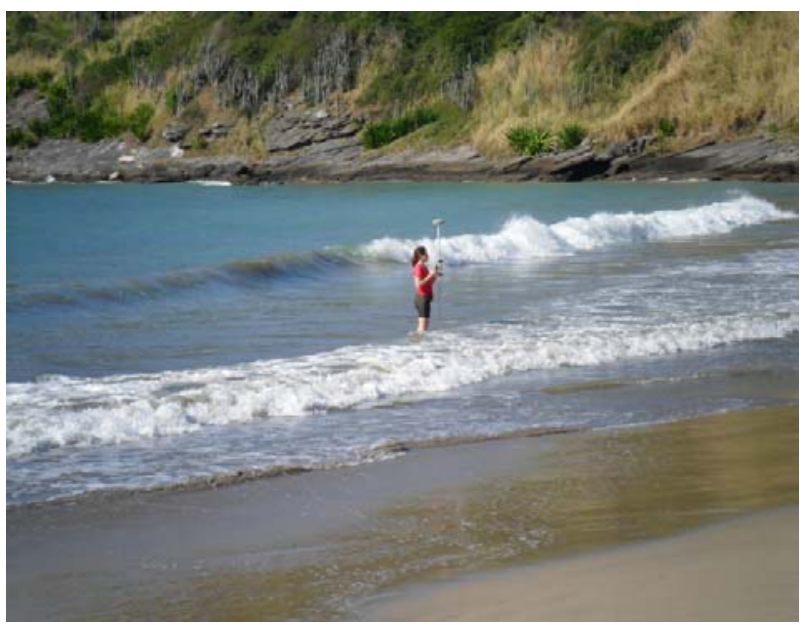

Figura 4: Aquisição de dados com utilização de DGPS no modo semicinemático na face da praia 


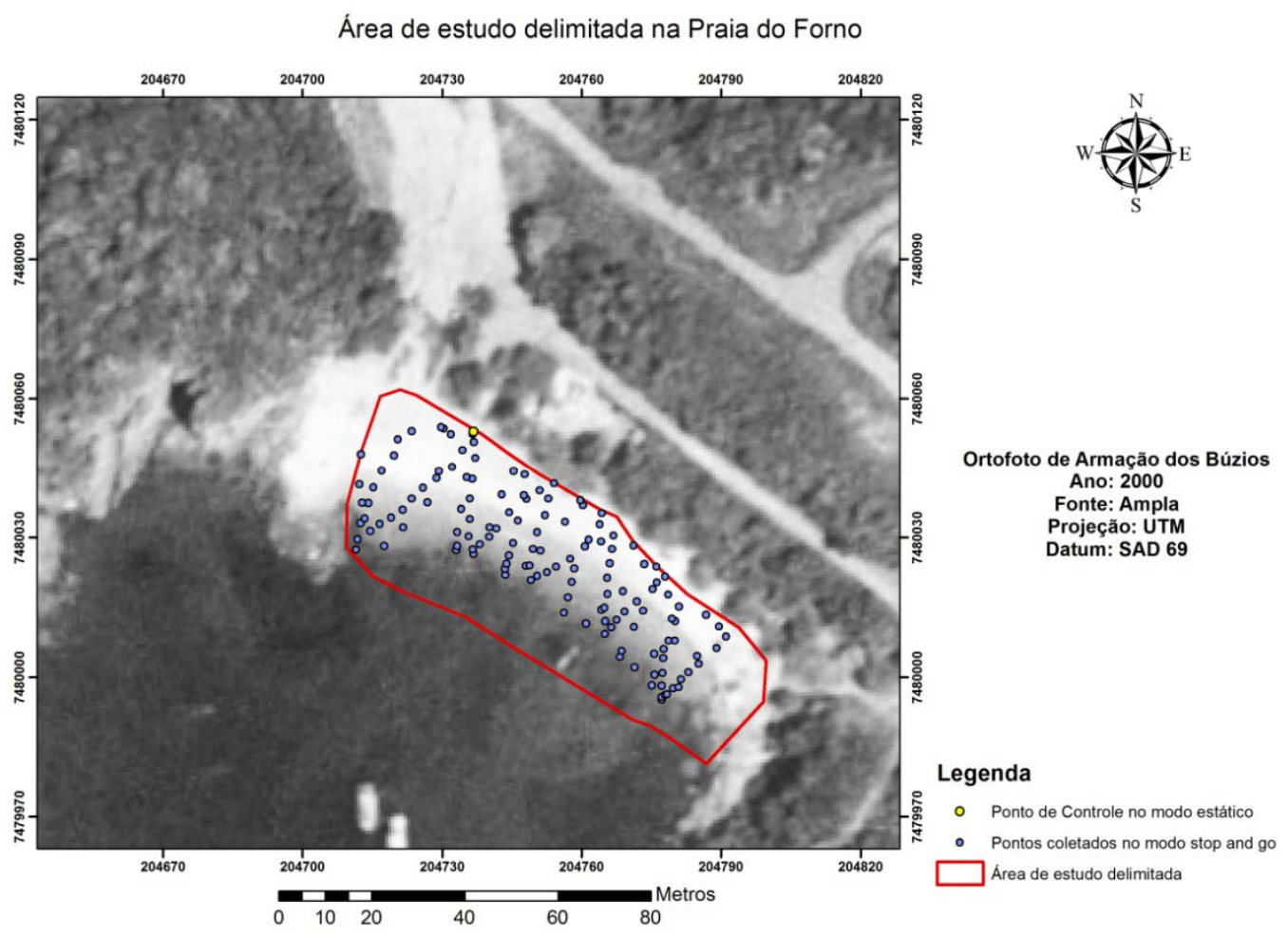

Figura 5: Mapa de localização de pontos coletados e de limites para a geração de MDT

\section{Resultados}

Para avaliar o modelo digital do terreno, são utilizados pontos de controle na área de estudo, determinados a partir de um levantamento relativo estático, no qual as coordenadas determinadas possuem precisão altimétrica de poucos centímetros, permitindo, portanto, ratificar a veracidade do modelo extraído através dos dados obtidos com GPS relativo no modo semicinemático.

No trabalho em questão foram determinadas as coordenadas de um único ponto de controle para avaliar a precisão do MDT. Suas coordenadas foram obtidas a partir de um levantamento relativo estático, utilizando um par de receptores de uma frequência, com duração de 1 hora de rastreio e linha de base de $5,8 \mathrm{~km}$. A altitude elipsoidal do ponto de controle no sistema WGS84 determinada a partir do processamento relativo das observações GPS foi de $-3,78 m$, com precisão de $0,01 \mathrm{~m}$, apresentando assim precisão suficiente para validar o MDT.

A partir da comparação das coordenadas do ponto de controle determinadas com GPS, com a altitude gerada pelo MDT para o mesmo ponto, pode-se estimar a precisão do MDT gerado. Neste caso, o ideal é que haja uma quantidade bem distribuída de pontos de controle (PC) na área a ser modelada.

Analisando o Ponto de Controle e o MDT, notou-se que estão de acordo, uma vez que a faixa do modelo onde se encontra o PC apresenta um intervalo que coincide com o valor do ponto. Além disso, com o objetivo de refinar a precisão do levantamento, foi identificado o valor de altimetria do pixel no MDT ($3,776 \mathrm{~m})$. Portanto, o MDT em questão apresenta precisão na casa dos centímetros. 
Modelo Digital do Terreno da Praia do Forno, Setembro 2011
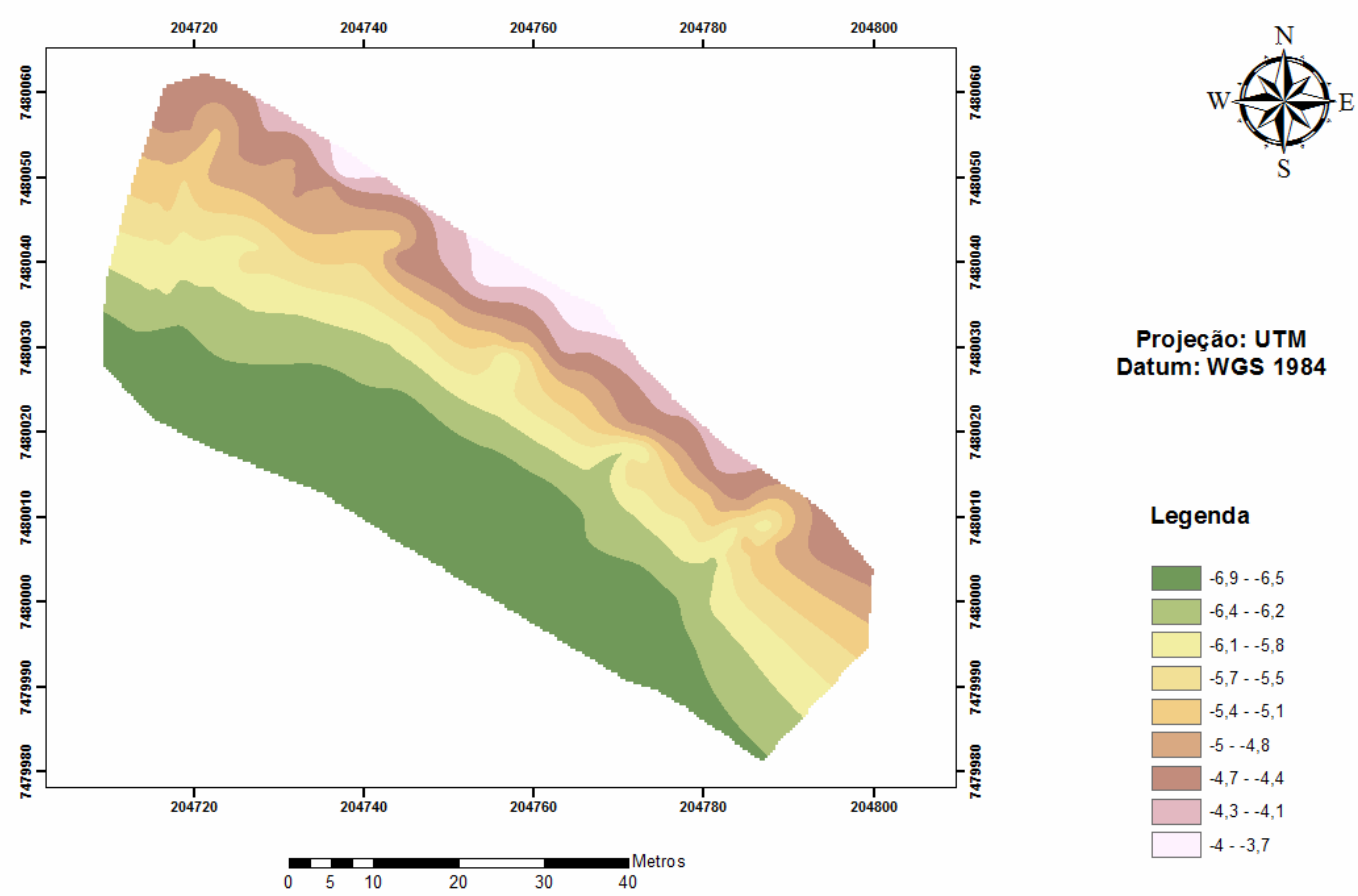

Projeção: UTM Datum: WGS 1984

Figura 6: MDT da Praia do Forno, setembro 2011

Modelo Digital do Terreno da Praia do Forno, Abril 2012
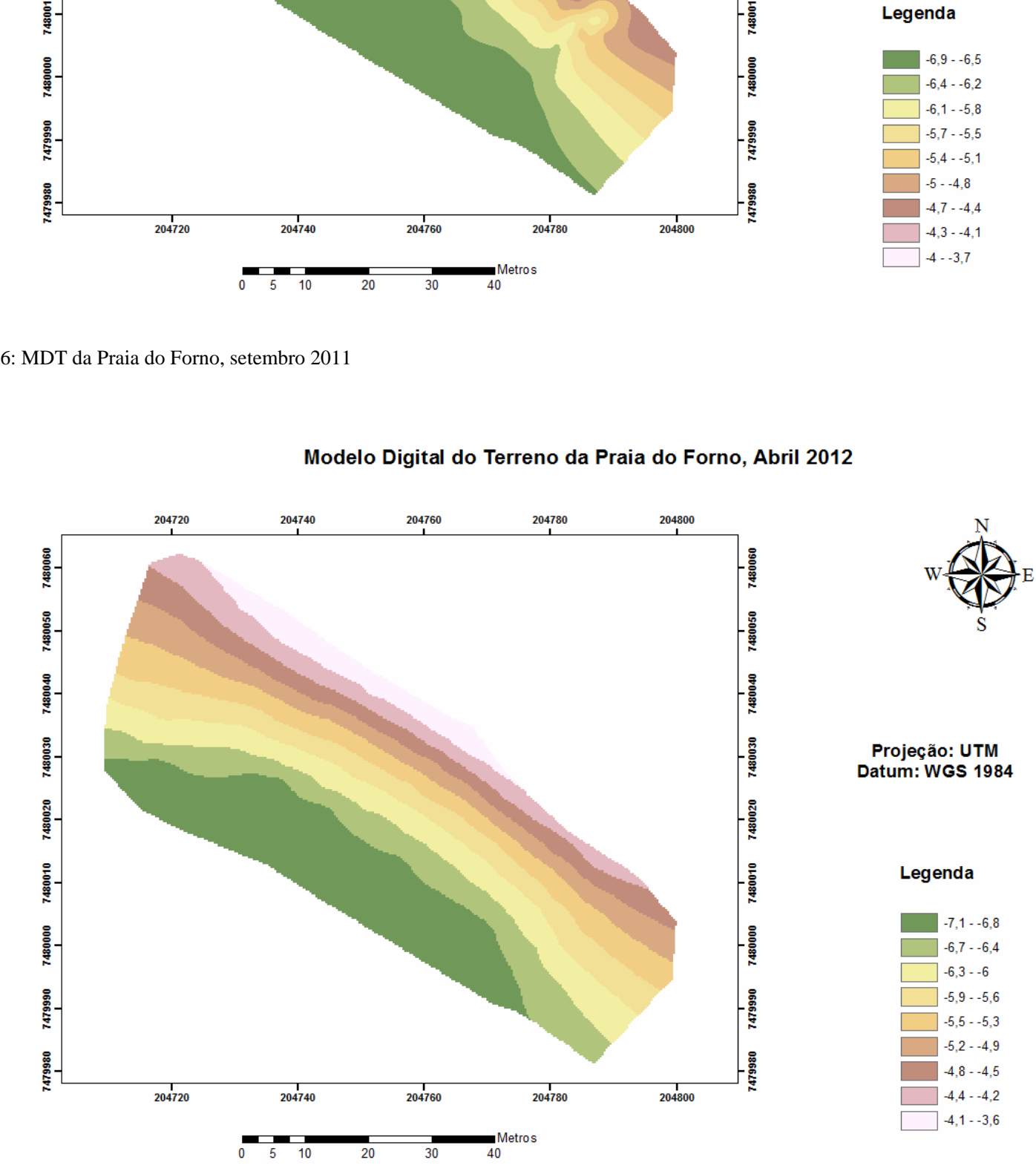

Figura 7: MDT da Praia do Forno, abril 2012 
Balanço sedimentar da Praia do Forno, Setembro 2011 - Abril 2012.

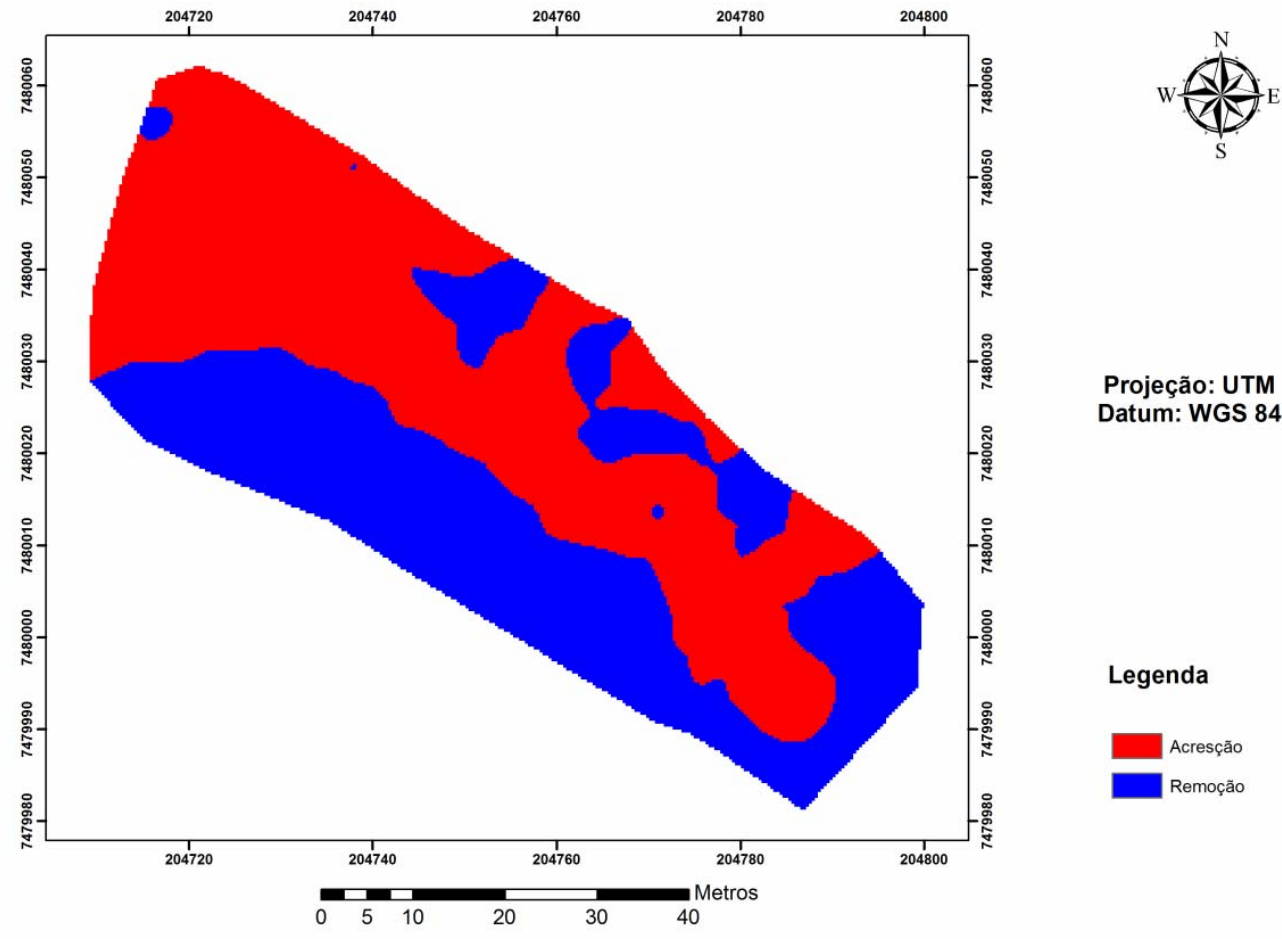

Figura 8: Subtração dos modelos das figuras 6 e 7, no programa ArcGis X

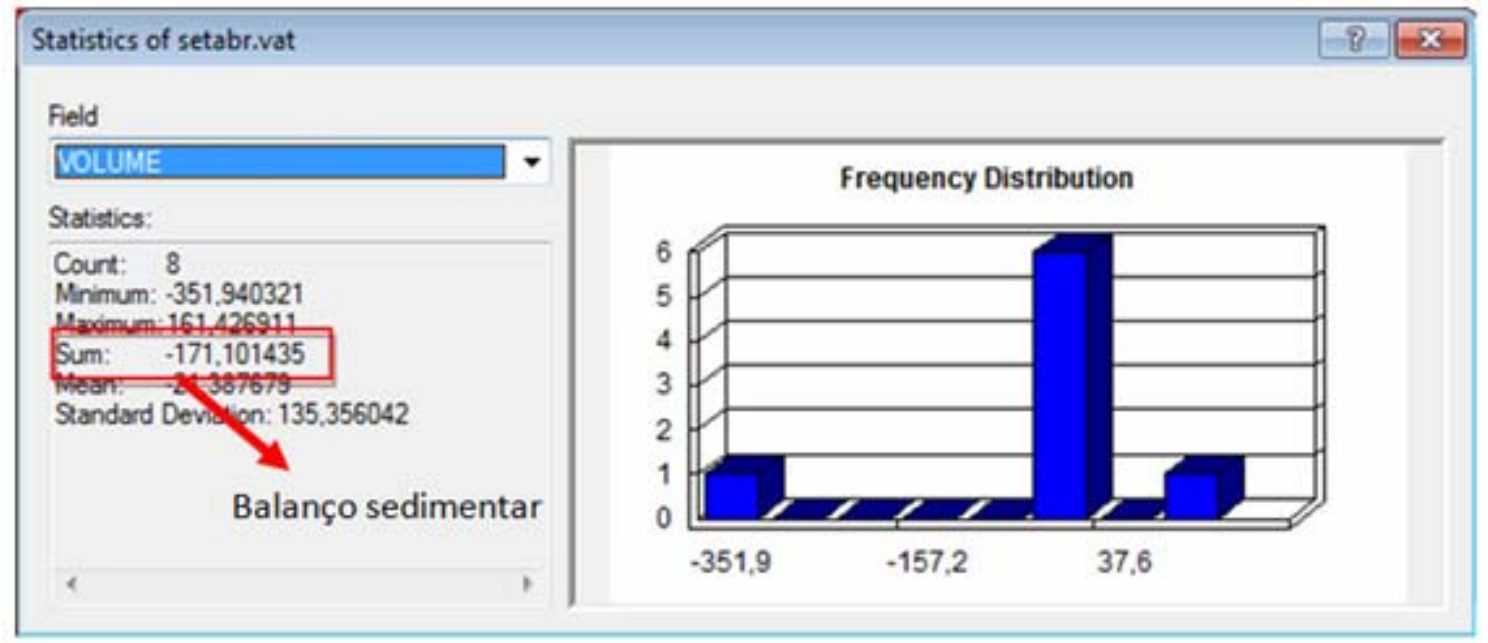

Figura 9: Estatísticas e resultado negativo do balanço sedimentar (em vermelho) dos modelos de setembro 2011 e fevereiro 2012

\section{Discussões}

Ao analisar a técnica descrita neste trabalho e a de Gonçalves et al. (2010), identificaram-se vantagens e desvantagens, porém as duas atenderam aos objetivos inicialmente elaborados para o monitoramento de ambientes costeiros. Ressalta-se que ambas apresentaram erros na captação de pontos. Com relação à metodologia deste trabalho, quando identificados pontos destoantes, realizou-se uma filtragem manual de acordo com as observações feitas em campo. Alternativas como a implantação de uma base mais próxima da área de estudo, aumento do tempo de rastreio, tempo maior de inicialização e um planejamento de campanha através da utilização do programa Mission Planning, que possibilita selecionar o melhor horário para o rastreio GPS, são opções que podem ser estudadas com o objetivo de melhorar o resultado do levantamento GPS, fazendo com que haja menor chance de se obterem pontos com informações equivocadas. Além disso, com o objetivo de confirmar a veracidade dos dados obtidos com GPS no modo semicinemático, foi coletado um ponto na praia com GPS no modo estático, que apresenta maior precisão do que o modo semicinemático. As informações obtidas através da operação do equipamento nos dois modos foram confrontadas, e os pontos com valores 
altimétricos significativamente diferentes foram descartados.

Na metodologia proposta por Gonçalves et al. (2010) também foram encontrados erros. Foram coletados pontos de controle com GPS de dupla frequência para comparar com os dados calculados através dos pares estereoscópicos e assim filtrar os pontos destoantes, estabelecendo através de cálculos estatísticos um desvio-limite entre os valores obtidos.

Levando em consideração os processos de aquisição de dados, nota-se uma logística mais complicada na metodologia proposta por Gonçalves et al. (2010), visto que é necessário o uso de uma aeronave especial para o tipo de trabalho que se pretende fazer, enquanto a metodologia descrita neste trabalho usa apenas alguns equipamentos de GPS que podem ser operados manualmente por uma só pessoa.

Outra questão a ser analisada refere-se ao tipo de área em que será utilizada cada metodologia. A técnica deste artigo é vantajosa apenas para ambientes de pequena extensão, visto que em faixas de grande extensão haverá um gasto de tempo muito grande, pois os aparelhos são operados manualmente por uma pessoa, enquanto a técnica utilizada por Gonçalves et al. (2010) é mais apropriada para ambientes de grande extensão, já que é realizada com ajuda de uma aeronave que tem facilidade para coletar informações de extensões maiores.

\section{Conclusões}

A metodologia proposta é eficiente para a geração de Modelos Digitais de Terreno e seu emprego no acompanhamento das variações do volume de praias. Foi possível identificar uma diferença de $171,101435 \mathrm{~m}^{3}$ entre os modelos de setembro e abril (figura 9), configurando um padrão erosivo na praia. Apesar disso, essa técnica possui limitações, o que faz com que seja aplicada de acordo com a análise da área de estudo, sendo importante observar seu tamanho, pois o método descrito neste trabalho é limitado em virtude da área de abrangência. O método é adequado a pequenas extensões, diferentemente do uso de fotografias tomadas de aviões, que têm a possibilidade de levantar áreas maiores. Outra limitação está relacionada ao levantamento da parte submersa, para o que outros equipamentos deveriam ser incorporados ao trabalho.

\section{Agradecimentos}

À FAPERJ, pela bolsa concedida. Aos colegas do curso de graduação em Geografia da UFF Bruno Dias, Marcos Caviare e Raquel Berlim. Às geólogas Raquel Batista e Roberta Moreno.

\section{Referências}

Amaro V.E., Araújo A.B. 2008. Análise Multitemporal da Morfodinâmica da Região Costeira Setentrional do Nordeste do Brasil entre os Municípios de Grossos e Tibau, Estado do Rio
Grande do Norte. Revista da Gestão Costeira Integrada, 8 (2): 77-100.

Bitar O.Y., Ortega R.D. 1998. Gestão Ambiental. In: Oliveira A.M.S., Brito S.N.A. (Eds.). Geologia de Engenharia. Associação Brasileira de Geologia de Engenharia (ABGE), São Paulo, 499-508 p.

Castro J.W.A, Fernandes D., Dias F.F. 2011. Monitoramento do processo de erosão costeira na praia das Tartarugas, Rio das Ostras - Estado do Rio de Janeiro / Brasil: Aplicação de metodologia quantitativa. Revista da Gestão Costeira Integrada, 11(3):355-368.

De Oliveira A.O., Calliari L.J. 2006. Morfodinâmica da Praia do Mar Grosso, São José do Norte/RS. Gravel, 4: 23-36.

Gonçalves J.A., Bastos L., Granja H.. Pinho J.L., Henriques R., Magalhães A. 2010. Monitorização de praias e dunas usando fotografia aérea digital com georreferenciação directa. In: ESIG 2010, Oeiras, Portugal.

Mazzer A.M., Dillenburg S. 2009. Variações temporais da linha de costa em praias arenosas dominadas por ondas do sudeste da Ilha de Santa Catarina (Florianópolis, SC, Brasil). Pesquisas em Geociências, 36: 117-135.

Monico J.F.G. 2007. Posicionamento pelo GNSS: Descrição, fundamentos e aplicações. UNESP, São Paulo, 480p.

Andrade M.S.C., Moreno R.S., Osilieri P.R.G., Berlim R., Dias F.F., Silva A.C., Seoane J.C.S., Castro J.W.A. 2011. Testes para geração de modelos em três dimensões da face da praia Brava, Armação dos Búzios, RJ, Brasil. In: XIV Colacmar, 2011, Balneário Camboriú-SC.

Nogueira J.D.L., Amaral R.F. 2009. Comparação entre os métodos de interpolação (Krigagem e Topo to raster) na elaboração da batimetria na área da Folha Touros. In: XIV Simpósio Brasileiro de Sensoriamento Remoto, 2009, Natal-RN. Anais... 4117-4123.

Pasolini A.. 2005. Análise morfodinâmica da praia de Marataízes frente a um possível processo de engordamento artificial. Monografia de Graduação. Departamento de Ecologia e Recursos Naturais, Universidade Federal do Espírito Santo, 60p.

Pereira R.S. 2008. Avaliação do risco geológico no arco praial do Peró - Município de Cabo Frio. Dissertação de Mestrado. PósGraduação em Geologia, Departamento de Geologia, Universidade Federal do Rio de Janeiro, 85p.

Rocha C.P., Araujo T.C.M., Mendonça F.J.B. 2010. Monitoramento de linha de costa usando posicionamento 3D-GPS. In: SIMGEO, Recife, Brasil.

Silva A.L.C., Silva M.A.M., Santos C.L. 2008. Comportamento morfológico e sedimentar da praia de Itaipuaçu (Maricá, RJ) nas últimas três décadas. Revista Brasileira de Geociências, 38: 8797.

Tabosa W.F. 2002. Monitoramento Costeiro das Praias de São Bento do Norte e Caiçara do Norte - RN: Implicações para o Pólo Petrolífero de Guamaré. Dissertação de Mestrado. PósGraduação em Geodinâmica e Geofísica, Centro de Ciências Exatas e da Terra, Universidade Federal do Rio Grande do Norte, 112 p. ${ }^{\text {i }}$ 